\title{
Pancreaticoduodenectomy for de novo ampulla of Vater cancer 15 years after living donor liver transplantation: a case report
}

\author{
Shin Hwang, Byeong-Gon Na, Sung-Min Kim, Geunhyeok Yang
}

Department of Surgery, Asan Medical Center, University of Ulsan College of Medicine, Seoul, Korea

Background: De novo malignancy sporadically occurs in patients who undergo liver transplantation. We present a case of a 74-year-old patient who underwent pancreaticoduodenectomy (PD) for de novo ampulla of Vater cancer at 15 years after living donor liver transplantation (LDLT) for hepatitis B virus-associated liver cirrhosis.

Case report: At 15 years after LDLT, elevation of liver enzyme levels led to diagnosis of de novo ampulla of Vater mass. We performed pylorus-resecting PD with extended pancreatic transection. Roux-en-Y choledochojejunostomy was performed to the remnant recipient-side proximal bile duct because active back bleeding from the bile duct stump was identified. The patient recovered uneventfully without complications. The surgical specimen showed a $2 \mathrm{~cm}$-sized moderately differentiated adenocarcinoma arising from a tubular adenoma of the intestinal subtype at the ampulla of Vater. The extent of the tumor was pT1bNOM0, thus being stage IB. Adjuvant chemotherapy was not performed. The patient has been doing well for 3 months. The immunosuppressive regimen was switched from mycophenolate mofetil monotherapy to everolimus monotherapy.

Conclusions: Our experience with this case suggests that PD can be eligibly performed after LDLT using duct-to-duct anastomosis.

Corresponding author: Shin Hwang

E-mail: shwang@amc.seoul.kr

(c) The Korean Society for Transplantation

This is an Open Access article distributed under the terms of the Creative Commons Attribution Non-Commercial License (http://creativecommons.org/licenses/by-nc/4.0/) which permits unrestricted non-commercial use, distribution, and reproduction in any medium, provided the original work is properly cited. 